\title{
Treatment of Pediatric-Onset Lupus Nephritis: A New Option of Less Cytotoxic Immunosuppressive Therapy
}

\author{
Hiroshi Tanaka ${ }^{1,2}$ and Tadaatsu Imaizumi ${ }^{3}$ \\ ${ }^{1}$ Department of School Health Science, Faculty of Education Hirosaki University, \\ ${ }^{2}$ Department of Pediatrics, Hirosaki University Hospital and \\ ${ }^{3}$ Department of Vascular Biology, Hirosaki University Graduate School of Medicine
}

Japan

\section{Introduction}

Optimal treatment for lupus nephritis in adolescents is still a great challenge. Systemic lupus erythematosus (SLE) is a chronic disease characterized by frequent disease flares for which effective and safe maintenance therapy is required (Chan et al., 2005; Lai et al., 2005). Since diffuse proliferative lupus nephritis (DPLN) is a major concern regarding treatment of young patients with SLE, the optimal immunosuppressive therapy for controlling the activity of DPLN in this population remains controversial (Niaudet, 2000; Tanaka et al., 2004, 2009). Intermittent monthly pulses of intravenous cyclophosphamide (CPA) have been reported to be effective even for patients with pediatric-onset SLE (Lehman \& Onel, 2000); however, CPA is a potent immunosuppressive agent associated with myelotoxicity, gonadal toxicity, and an increased risk of secondary malignancy (Chan et al., 2000; Lai et al., 2005). Since therapy related-adverse events are a major therapeutic risk of the immunosuppressive treatment in patients with SLE, selecting a safe and effective treatment protocol poses a big dilemma for physicians treating young patients. Thus, optimal maintenance treatment for controlling the clinical activity of SLE, particularly in young patients with pediatric-onset SLE, remains to be established (Yang et al., 1994; Niaudet, 2000; Tanaka et al., 2001).

Mycofenolate mofetil (MMF) has recently been reported to be as effective as and less toxic than oral CPA or monthly intermittent pulse therapy with intravenous CPA (iv-CPA) for SLE patients (Chan et al., 2000; Lai et al., 2005; Sinclair et al., 2007). However, clinical use of MMF, in patients other than those undergoing solid organ transplantation, has not been approved by the Japanese Ministry of Health and Welfare yet. On the other hand, mizoribine (MZR), a selective inhibitor of inosine monophosphate dehydrogenase in the de novo pathway of purine nucleotides, which acts very similar to MMF (Burkhardt \& Kalden, 1997; Yokota, 2002), has been successfully used without any serious adverse effects for the long-term treatment of young patients with lupus nephritis (Tanaka et al., 2004; Yumura et al., 2005). We hypothesized that calcineurin inhibitors, other than MZR, might be a feasible alternative treatment for patients with pediatric-onset lupus nephritis (Tanaka et al., 2007a, 2009). Tacrolimus (Tac) is a T-cell-specific calcineurin inhibitor that prevents the activation of helper $\mathrm{T}$ cells, thereby inhibiting the transcription of the early activation genes of interleukin (IL)-2 
and suppressing the T cell-induced activation of tumor necrosis factor (TNF)- $\alpha$, IL-1 $\beta$ and IL-6 (Kawai \& Yamamoto, 2006). Therefore, Tac is an attractive therapeutic option for young patients with lupus nephritis. We believe that both MZR and Tac may be new options of less cytotoxic immunosuppressive therapy for pediatric patients with lupus nephritis. Recently, a multidrug regimen comprising prednisolone (PDN), Tac, and MMF has been reported to be safe and effective for the treatment of adult lupus (Lanta et al., 2010). We also propose that as an alternative to CPA, a multidrug therapy consisting the immunosuppressive agents, MZR and Tac, which have different modes of action, combined with PDN would be an effective and safe treatment for pediatric-onset SLE (Watanabe et al., 2011).

From our recent clinical experiences, we would like to introduce this new less cytotoxic immunosuppressive therapy for the treatment of pediatric-onset lupus nephritis. Furthermore, we would like to discuss the novel signaling pathways in mesangial cells, which may be involved in the pathogenesis of lupus nephritis.

\section{A new option of less cytotoxic immunosuppressive therapy for pediatric- onset lupus nephritis}

Recent advances in the management of lupus nephritis, together with earlier renal biopsy and selective use of aggressive immunosuppressive therapy, have contributed to a favorable outcome in children and adolescents with SLE (Yang et al., 1994; Niaudet, 2000; Tanaka et al., 2001). Nevertheless, for optimal control of the activity of lupus nephritis, we believe that more effective and less toxic treatment strategies need to be developed. Although it has been reported that iv-CPA is effective for preserving renal function in adult patients (Austin \& Balow, 1999), CPA is a potent immunosuppressive agent that induces severe toxicity, including myelotoxicity, gonadal toxicity, and an increased risk of secondary malignancy (Chan et al, 2000). Thus, the optimal treatment strategy for controlling the activity of lupus nephritis, especially in children and adolescents, is still controversial (Niaudet, 2000; Tanaka et al., 2004).

\subsection{Mizoribine, a selective inhibitor of inosine monophosphate dehydrogenase in the de novo pathway}

The mode of action of mizoribine (MZR) is, very similar to that of MMF, owing to the selective inhibition of inosine monophosphate dehydrogenease (IMPD) in the de novo pathway of purine nucleotide synthesis. MZR inhibits $\mathrm{T}$ cell and B cell proliferation (Burkhardt \& Kalden, 1997; Yokota, 2002). MZR inhibition of IMPD is competitive and different from that induced by MMF (Sonda et al., 1996). Indeed, it has been reported that the concentrations of MZR required to effectively inhibit human mixed-lymphocyte reaction, must reach peak blood levels ranging approximately from 3.0 to $6.0 \mu \mathrm{g} / \mathrm{mL}$, while beyond the $6.0 \mu \mathrm{g} / \mathrm{mL}$ level, it may lead to myelotoxicity (Sonda et al., 1996). It has also been reported that following MZR administration, 14-3-3 proteins, that is, MZR-binding proteins in vivo, interact with glucocorticoid receptors to enhance the transcriptional activity of these receptors (Takahashi et al., 2000). In vitro, the MZR concentration required to effectively enhance steroid receptor activity has been reported to be more than $10 \mu \mathrm{M}$, which corresponds to a blood MZR level of approximately $2.6 \mu \mathrm{g} / \mathrm{mL}$. Clinically, MZR has been successfully used without any serious adverse effects for the long-term treatment of young patients with lupus nephritis (Tanaka et al., 2004; Yumura et al., 2005). Based on previous clinical observations, the efficacy of MZR may depend on the peak serum level of the drug 
(Tanaka et al., 2003; Nozu et al., 2006; Kuroda et al., 2007). In addition, it has been reported that a peak serum MZR level of at least 2.5-3.0 $\mathrm{\mu g} / \mathrm{mL}$ may be needed to effectively suppress of serum anti-dsDNA antibody titers and attain satisfactory clinical efficacy in lupus nephritis patients (Tanaka et al., 2005). However, when using MZR with the conventional protocol of low-dose (3-4 mg/ $\mathrm{kg}$ ) daily MZR (MZR-C) in young patients with lupus nephritis, the peak blood level of the drug usually remains at around $1.0 \mu \mathrm{g} / \mathrm{mL}$ (Tanaka et al., 2003), which may explain the relatively mild efficacy of MZR observed in clinical practice (Kuroda et al., 2007).

In this context, we conducted a trial of relatively long-term (at least 12 months or longer) intermittent pulse therapy with oral MZR (up to $10 \mathrm{mg} / \mathrm{kg}$ as a single dose before breakfast on 2 days of the week, MZR-P), to attain increased peak blood levels of MZR, in young patients with flares of lupus nephritis (Tanaka et al., 2008a). Our results suggested that this new treatment protocol was beneficial and resulted in higher efficacy and lower toxicity, in terms of reduction of proteinuria, decrease in the serum anti-dsDNA antibody titer, recovery of hypocomplementemia, preservation serum creatinine level, and decrease in the European Consensus Lupus Activity Measurement index (ECLAM) (Masca et al., 2000) than the MZR-C (Tanaka et al., 2008a and b). The rationale for using MZR-P was as follows: 1) MZR is rapidly excreted into the urine: about $90 \%$ of the drug is completely eliminated from the circulation within about 12 hours after oral intake; thus, the accumulation of the drug is not considered to be a problem, at least under the condition of normal renal function (Yokota, 2002). Considering this point, the intermittent use of high-dose MZR may be relatively safe. 2) Higher doses of MZR increase the area under the serum concentrationtime curve (AUC) in lupus patients (Yumura et al., 2005); thus, the efficacy of MZR may depend on the peak serum level of the drug, which, in turn, may be closely correlated with the AUC of the drug (Tanaka et al., 2003). 3) In an SLE mouse model, the intermittent administration (every other day) of MZR effectively reduced anti-DNA antibody production (Kamata et al., 1984). In our recent multicenter study, we confirmed that the MZR-P protocol was more effective than the MZR-C protocol, with no serious adverse events occurring during the long-term treatment of young patients with DPLN (Tanaka et al., 2008a). Also, MZR-P showed the potential usefulness of MZR-P as induction therapy in young patients even in those with DPLN (Tanaka et al., 2008a and b). Follow-up renal biopsy specimens obtained after the initiation of MZR-P revealed an apparent improvement in the 2003 classification of lupus nephritis by the International Society of Nephrology/Renal Pathology Society (ISN/RPS), with a decrease in the activity indices without a significant progression in the chronicity indices described by Austin et al. (1984). It is noteworthy that no clinical toxicity, not even amenorrhea- a serious problem in female patients, occurred in any of the study patients. This low clinical toxicity is an important advantage of MZR-P treatment, especially for long-term treatment of young patients.

Besides its immunosuppressive effects, MZR has recently been reported to suppress the progression of histologic chronicity in selected patients with lupus nephritis and IgA nephropathy (Kawasaki et al., 2004; Tanaka et al., 2007b and c; Ikezumi et al., 2008). Moreover, MZR has been reported to attenuate tubulointerstitial fibrosis in a dosedependent manner in rat models of unilateral ureteral obstruction, non-insulin-dependent diabetes and peritoneal fibrosis via suppression of macrophage infiltration of the interstitium (Sato et al., 2001; Kikuchi et al., 2005; Takahashi et al., 2009). Interestingly, MZR has been reported to bind specifically to heat shock protein (HSP) 60, which results in interference of the chaperone activity of HSP60 in vitro (Itoh et al., 1999). This may, in turn, lead to suppression of the activity of a $3 \beta 1$-integrin, which is known to play a role in the 

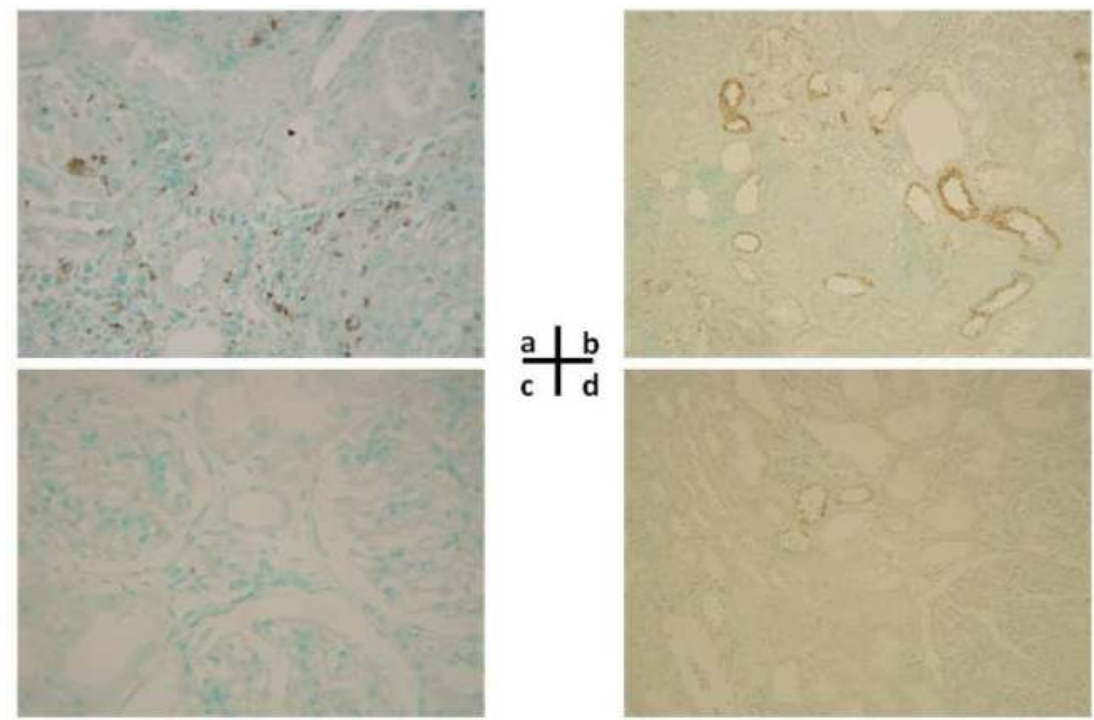

Pre-treatment renal biopsy specimen of a patient with diffuse proliferative lupus nephritis (DPLN) showing numerous CD68-positive cells (a), and the area expressing osteopontin (b) Post-MZR treatment renal biopsy specimen of a patient with DPLN who received MZR treatment showing a significant decrease in the infiltration by CD68-positive cells (c) associated with markedly decrease in the area expressing osteopontin (d)

Fig. 1. (Tanaka H, et al. Clin Rheumatol 2010)

development of interstitial fibrosis. Indeed, in a clinical setting, it has also been reported that posttreatment renal biopsy specimen from patients with severe IgA nephropathy treated with MZR, showed marked attenuation of glomerular and interstitial lesions, and significantly reduced the number of activated macropharges, associated with the expression of 14-3-3 proteins and HSP60, which are known to be MZR-binding proteins, in the inflamed glomerular cells (Ikezumi et al., 2008). Thus, it is speculated that MZR may bind directly to inflamed glomerular cells and prevent progressive damage by suppressing activated macrophages and intrinsic renal cells. Therefore, MZR itself may have a favorable effect against the progression of interstitial fibrosis in the diseased kidney. These laboratory and clinical observations suggest another beneficial mechanism of action of MZR in the treatment of renal diseases. From our recent study, we confirmed the reported beneficial histologic effects of MZR, that is, we found a significant suppression of intraglomerular macrophage infiltration accompanied with significant suppression of the chronicity indices following MZR treatment (Tanaka et al., 2010). MZR treatment also resulted in a decreasing tendency of interstitial macrophage infiltration and the expression of osteopontin, known to be a chemoattractant protein for macrophages (Fig. 1). Since the inflamed glomeruli express 14-3-3 proteins and HSP60 (Ikezumi et al., 2008), MZR may directly interact with inflamed glomerular cells, because MZR is directly excreted into the urine. Moreover, Takeuchi et al. (2010) reported that MZR directly prevented podocyte injury in experimental puromycin aminonucleoside-induced nephropathy, suggesting an anti-proteinuic effect of MZR besides its immunosuppressive effects. These beneficial mechanisms of action of MZR would warrant its use in the treatment of patients with lupus nephritis, although this theory 
remains speculative. We suspect that this mechanism may represent a mode of action different from that of MMF, although we could not demonstrate whether MZR was superior to MMF treatment for DPLN patients.

Further detailed studies involving a larger number of patients are needed to draw a conclusion. We believe that MZR is an attractive treatment for young patients with lupus nephritis because of attenuated histologic progression resulting from a suppressed accumulation of activated macrophages in the glomeruli. From the view point of the balance between suppression of disease activity and the adverse effects of treatment, we believe that long-term MZR treatment, including use of our MZR-P protocol, may become the new treatment of choice for young patients with lupus nephritis.

\subsection{Tacrolimus, a calcineurin inhibitor}

Some studies have recently suggested that cyclosporine A (CsA), a calcineurin inhibitor similar to Tac, might replace cytotoxic agents and reduce the dosage of concomitantly administered PDN for maintenance therapy in selected patients with lupus nephritis (Rihova et al., 2007; Moroni et al., 2008). It has been reported CsA treatment has beneficial effects in some pediatric patient with SLE resistant to conventional immunosuppressive therapy, including iv-CPA (Sakano et al., 2004; Suzuki et al., 2006). However, CsA-related nephrotoxicity, posterior reversible encephalopathy syndrome, as well as unfavorable cosmetic effects, such as hypertrichosis and gingival hypertrophy, remain major concerns for young patients with SLE, especially female adolescents.

Tacrolimus (Tac) is a T cell-specific calcineurin inhibitor that prevents activation of helper $\mathrm{T}$ cells, thereby inhibiting transcription of the early activation genes of IL-2 and suppressing the production of TNF- $\alpha$, IL-1 $\beta$, and IL-6. Considering its effects, Tac is expected to have clinical benefits in the treatment of patients with active SLE. Indeed, to date several papers have described the efficacy and safety of Tac in patients with active SLE (Duddridge \& Powell, 1997). Recently, Tac combined with PDN has been successfully administered without serious adverse effects, as induction and maintenance treatment for patients with proliferative and membranous lupus nephritis (Politt et al., 2004; Maruyama et al., 2005; Mok et al., 2005; Tse et al., 2007; Szeto et al., 2008). However, there is little information regarding the efficacy and safety of Tac in young patients with lupus nephritis (Tanaka et al., 2007a, 2009). The safety of Tac treatment is important because of its potent nephrotoxicity. Although these patients did not necessarily have permanently high blood levels of Tac (Duddridge \& Powell, 1997; Tse et al., 2007), the development of an optimal Tac treatment strategy for lupus nephritis, with a dose as low as possible, is sought to minimize treatment toxicity while maintaining treatment efficacy. In this context, in Japan, Tac is usually administered once daily for patients with rheumatoid arthritis (RA) or lupus nephritis since once-daily administration of Tac is the governmental approved protocol (Kawai \& Yamamoto, 2006; Tanaka et al., 2007a, 2009; Asamiya et al., 2009). Kawai and Yamamoto (2006) reported the safety of Tac administered at a dose of 1.5-3.0 mg once daily for the treatment of RA even in the elderly. Although further studies, including a histologic evaluation following Tac treatment, are needed, we consider that a once-daily regimen could shorten the exposure to Tac, would be more cost-beneficial than the conventional twice-daily protocol, and might result in better treatment compliance. Interestingly, Tac has been reported to stimulate glucocorticoid receptor (GR) transactivity through its ligands (Davies et al., 2005), which may explain the tendency to exacerbate glucose intolerance in selected patients (Mok et al., 2005). However, some patients who had experienced new flares 
of SLE while receiving CsA were successfully treated with Tac (Tanaka et al., 2007a, 2009). Differential control of the GR hormone-binding function by immunosuppressive ligands, such as Tac, reportedly stimulates GR transactivity beyond the effect of the ligand on hormone retention although this is not the case with CsA (Davies et al., 2005). These laboratory observations may explain the superior effect of Tac to that of CsA in selected patients with lupus, although this hypothesis remains speculative.
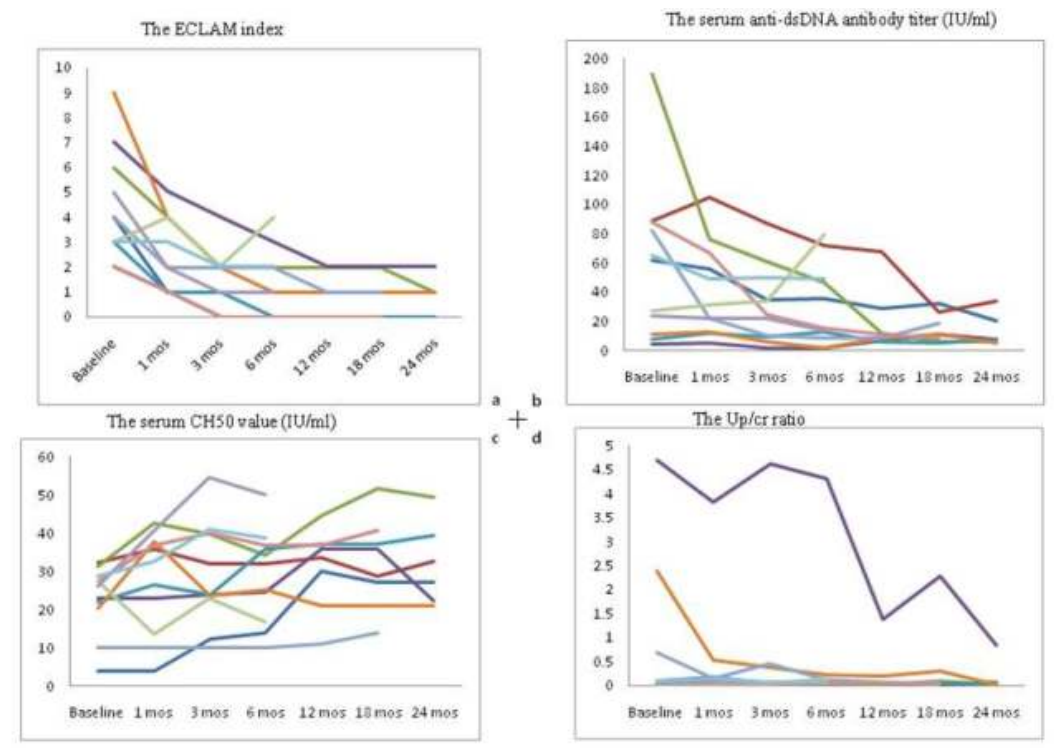

Individual changes in the ECLAM index (a), the serum anti-dsDNA antibody titer (b), the serum complement hemolytic activity (CH50) value (c) and the urinay protein/creatinone (Up/cr) ratio (d) in patients with lupus nephritis (LN) treated with tacrolimus administered once daily. A significant decrease in the ECLAM index was noted after 1 month treatment (a). A significant decrease was also noted in the serum anti-dsDNA antibody titer and the serum CH50 value after 3 months treatment $(b$, c). One patient with class V LN associated with massive proteinuria showed a significantly decrease in the $\mathrm{Up} / \mathrm{cr}$ ratio after 12 months treatment (d).

Fig. 2. (Tanaka H, et al. Clin Nephrol 2009)

In our recent study, 11 consecutive patients with long-standing biopsy-proven lupus nephritis were recruited for at least 6 months or longer (6-24 months) as part of an openlabel trial of single-daily-dose administration of Tac ( $3 \mathrm{mg} /$ day, $0.04-0.075 \mathrm{mg} / \mathrm{kg}$ ). As a result, despite the gradual tapering of the PDN dose, a marked improvement of the ECLAM index, compared with the baseline values, was observed even at 1 month after the start of treatment and in the serological parameters at 3 months. These favorable results persisted until the end of the study. Proteinuria gradually decreased and had dropped significantly by 24 months after the start of treatment (Fig. 2). After a mean of 18 months, a complete response was achieved in 8 patients $(73 \%)$ and a partial response was achieved in two patients (Tanaka et al., 2009). Adverse reactions to Tac treatment were not severe and were well tolerated. Although the blood levels of Tac in the participants ranged from $1.5 \mathrm{ng} / \mathrm{mL}$ to $7.5 \mathrm{ng} / \mathrm{mL}$, no definite relationship between the efficacy of the drug and its blood level was noted. Even though the absorption profile of Tac showed some variations among the 
study patients, the appropriate blood levels and doses of Tac for the treatment of young patients with lupus nephritis remains to be determined. Measuring the AUC in the pharmacokinetic profile of Tac obtained from each patient is also needed to confirm whether its efficacy depends on its blood levels. From our recent studies, although further studies involving a larger number of patients, including a histologic evaluation following Tac treatment, are needed, we believe that low-dose Tac treatment, administered once daily, may be an effective and safe method for managing selected young patients with pediatriconset, long-standing lupus nephritis (Tanaka et al., 2007, 2009).

Tac has been reported to reduce proteinuria and mesangial alterations due to its suppressive effects on glomerular expression of IFN-ץ mRNA in rat models (Ikezumi et al., 2002) In addition, it has recently been reported that Tac may overcome treatment unresponsiveness through the blockade of the drug exclusion effect of P-glycoprotein, leading to restoration of the intracellular therapeutic levels of corticosteroids and clinical improvement (Suzuki et al., 2010). These laboratory and clinical observations suggest that Tac might have other useful mechanisms of action besides its immunosuppressive effects, which would warrant its use in the treatment of patients with active and steroid-resistant SLE with lupus nephritis.

\subsection{New multidrug therapy using tacrolimus and mizoribine}

Combination therapy consisting of two immunosuppressive agents with different modes of action is useful and frequently used for immunosuppression in solid organ transplantation. The efficacy of multidrug therapy using MMF and Tac as induction therapy in patients with class V+IV lupus nephritis (DPLN with membranous lesions; Bao et al., 2008), has recently been reported. This multidrug therapy resulted in less cytotoxicity than iv-CPA therapy; the authors concluded that multidrug therapy MMF and Tac was superior to iv-CPA for inducing remission of class V+IV lupus nephritis and was well tolerated. Also, Lanta et al. (2010) reported the efficacy of adding Tac to the MMF plus PDN treatment regimen in some patients with DPLN resistant to MMF and PDN, although clinical toxicity, such as ketoacidosis, infections and muscle pain, limited the use of this combination therapy. Since the mechanisms of action of MMF and Tac are probably complementary, these clinical observations suggested the potential usefulness of multidrug therapy for the treatment of lupus nephritis. However, therapy related-adverse events remain a major therapeutic risk of the immunosuppressive treatment for patients with lupus patients.

The inhibitor of purine synthesis, MZR has reportedly exhibits relatively low clinical toxicity in patients with lupus nephritis (Tanaka et al., 2004; Yumura et al., 2005). Interestingly, aside from its immunosuppressive effect, MZR also appears to have a beneficial effect against the adverse effects of calcineurin inhibitors, such as CsA-induced intimal hyperplasia and perivascular inflammatory cell infiltration observed in rat models (Shimizu et al., 2003; Hara et al., 2009). We recently documented significant suppression of intraglomerular and interstitial macrophage infiltration accompanied by significant suppression of chronicity indices following MZR treatment in patients with lupus nephritis (Tanaka et al., 2010). Thus, we speculate that these histological observations may further support the use of MZR to treat selected patients with glomerular diseases, especially those treated with calcineurin inhibitors, such as CsA or Tac. Moreover, we hypothesized that combination therapy using low-dose Tac administered once-daily and MZR, instead of MMF, might be a beneficial alternative for the treatment of pediatric-onset refractory renal diseases including lupus nephritis (Aizawa-Yashiro et al., 2011; Watanabe et al., 2011). 
We present here typical cases of pediatric-onset lupus nephritis in which the efficacy and safety of our novel multidrug therapy were observed. Patient 1 was an 11-year-old Japanese girl with a 2-year history of SLE with ISN/RPS classification class V lupus nephritis. She suddenly developed refractory epistaxis due to severe thrombocytopenia $(7,000 / \mu \mathrm{L})$ associated with serum $\mathrm{C} 4$ depression. The patient had been successfully managed with PDN combined with Tac. Consequently, the patient was given an emergency intravenous infusion of high-dose immunoglobulin, which transiently raised her platelet count to $36,000 / \mu \mathrm{L}$. Because the patient was in a near-pubertal state, we avoided the use of iv-CPA. Thus, we used MZR in addition to Tac. After this combination therapy, her platelet count remained normal at 200,000/ $\mu \mathrm{L}$. The dose of concomitantly administered PDN was tapered without recurrence of thrombocytopenia. At present, 18 months after administration of this therapy, she is free of SLE signs and symptoms without therapy-related clinical toxicity (Watanabe et al., 2011). Patient 2 was a 14-year-old Japanese girl. She was treated with PDN because of hemophagocytic syndrome that she had developed 6 months earlier. When PDN was tapered, she developed malar rash, significant proteinuria/hematuria, hypocomplementemia and elevation of serum anti-dsDNA antibody titers. Percutaneous renal biopsy revealed ISN/RPS class IIIa lupus nephritis (activity index, 8; chronicity index, 2). She was administered 2 courses of methyprednisolone pulse therapy followed by multidrug therapy consisting of Tac, MZR and PDN. Because she was of pubertal age, the PDN dose was reduced to a minimum at a relative early stage. Her clinical and laboratory signs improved, and the second renal biopsy, performed 12 months after the initial biopsy, revealed marked improvement to ISN/RPS class II lupus nephritis (activity index, 4; chronicity index, 1) without any significant increase in the number of chronic lesions. At present, 36 months after the start of the administration of this therapy, she is free of SLE signs and symptoms without therapy-related clinical toxicity. In lupus nephritis patients, it is well known that flares may occur during long-term immunosuppressive treatment, even after at least a 12 month-long successful treatment with MMF or MZR (Tanaka et al., 2006; Posalski et al., 2009). Although the optimal treatment strategy for managing long-standing SLE, especially in pediatric patients, remains controversial, we believe that our treatment protocol is both effective and safe, and also easy to comply with for patients with pediatriconset lupus. However, the long-term efficacy and safety of this regimen remains unclear. Further studies in a larger number of young patients with lupus nephritis are necessary to confirm the long-term efficacy and safety of our current protocol.

\section{A potential new therapeutic strategy for pediatric-onset lupus nephritis: targeting the IFN regulatory factor signaling pathways}

Recently, the importance of innate immunity in the pathogenesis of glomerulonephritis has been reported (Robson, 2009; Coppo et al., 2010). Toll-like receptors (TLRs), which are cell surface and intracelluar receptors for pathogen-associated molecules, play a central role in the response of both the innate and adaptive immune systems to microbial ligands (Robson, 2009). Once presumptive antigenic ligands bind to TLRs, the activation of transcriptional factors, such as interferon regulatory factors (IRF) and nuclear factor kappa B (NF-KB) is induced through intracellular signaling cascade activation. The activation results in the release of adhesion molecules, cytokines and chemokines, which play a pivotal role in the innate and adaptive immune responses (Coppo et al., 2010). Interestingly, recent studies revealed the expressions of TLRs in resident renal cells, suggesting the involvement of the TLR signaling pathway in the pathogenesis of glomerular diseases (Patole et al., 2006). 


\subsection{The retinoic acid-inducible gene-I (RIG-I) and lupus nephritis}

Retinoic acid-inducible gene-I (RIG-I) encodes a DExH box protein, which is a RNA helicase. The DExH box family of proteins regulates RNA metabolism and has various biological functions. Like toll-like receptor (TLR)-3, RIG-I may detect viral RNAs and mediate immune reactions against RNA viruses (Yoneyama et al., 2004). RIG-I has also been suggested to be involved in immune and inflammatory responses in various physiological and morbid conditions (Imaizumi et al., 2009)

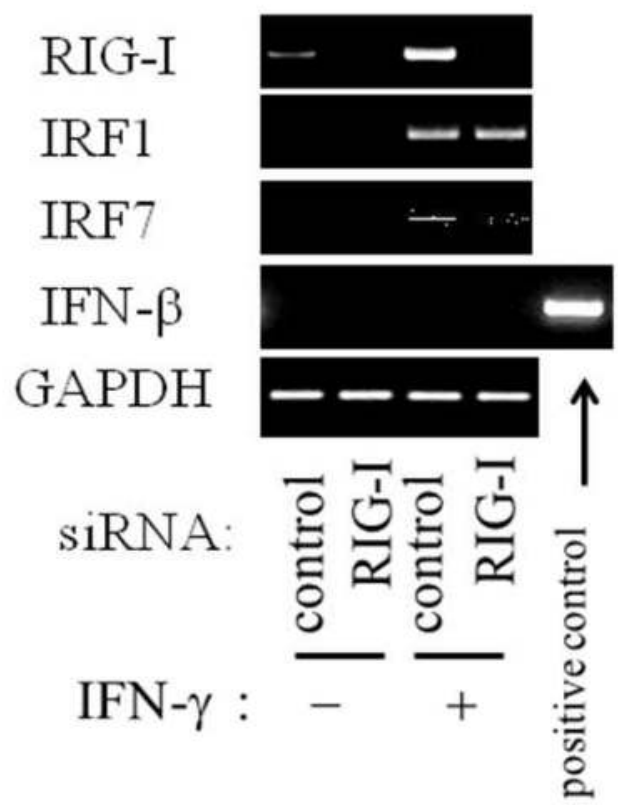

The cells were transfected with siRNA against RIG-I or a negative control non-silencing siRNA. At $24 \mathrm{~h}$ after the transfection, the cells were treated with $5 \mathrm{ng} / \mathrm{ml} \mathrm{IFN- \gamma}$ for $24 \mathrm{~h}$. RNA was extracted from the cells and RT-PCR analyses for RIG-I, IRF1, IRF7, IFN- $\beta$ and GAPDH were performed.

Fig. 3. (Imaizumi et al., Lupus 2010)

In a recent study, we showed that RIG-I controlled the immune and inflammatory responses by regulating the expression of various downstream genes, including IFNs regulatory factor (IRF) genes, in mesangial cells (Imaizumi et al., 2010). We previously found RIG-I was highly expressed in the glomeruli examined in biopsy specimens from patients with lupus nephritis, and the level of expression correlated with the severity of acute inflammatory lesions (Suzuki et al., 2007). In addition, we found that the levels of RIG-I mRNA in the urinary sediment of patients with lupus nephritis were higher than those in patients with IgA nephropathy and controls (Tsugawa et al. 2008). Interestingly, repeated measurements of RIG-I mRNA in the urinary sediment of lupus patients revealed a reduction of the expression following immunosuppressive treatment (Tsugawa et al., 2008). These findings suggest that RIG-I may be involved in the acute inflammatory process in human lupus nephritis. In order to examine the involvement of RIG-I in lupus nephritis, we conducted experimental studies using human mesangial cells. Because Th1-derived cytokines are known to be key mediators in the 
progression of lupus-associated renal injury, and IFN-ץ is one of the major Th1 type cytokines with potent proinflammatory effects that exerts its effects through the upregulation of IFNinducible genes (Patole et al., 2006), we examined the effects of IFN- $\gamma$ on the expression of RIGI in human mesangial cells. As a result, IFN- $\gamma$ treatment resulted in a concentration-dependent upregulation of the expression of RIG-I mRNA and protein in human mesangial cells. Treatment of cells with IFN-y also induced the expression of mRNA of both IRF 1 and IRF7, which are important IFN-inducible transcriptional factors. Furthermore, knockdown of RIG-I expression by RNA interference inhibited the IFN- $\gamma$-induced expression of IRF7, but not that of IRF1. In contrast, IFN- $\gamma$ did not induce the expression of IFN- $\beta$, which is known to be a target gene of IRF-7, in mesangial cells (Fig. 3) (Imaizumi et al., 2010)

Interestingly, pretreatment of cells with dexamethasone inhibited the IFN- $\gamma$-induced expression of monocyte chemoattractant protein (MCP)-1 mRNA but did not affect the induction of RIG-I or IRF7 mRNA in mesangial cells. The induction of MCP-1 mRNA by IFN- $\gamma$ was not inhibited by the knockdown of NF-kB p65, indicating that the NF-kB signaling pathway was not involved. Our results suggest selective regulation of the expression of IRFs by RIG-I in human mesangial cells. The function of IRF7 has been well studied, mainly in dendritic cells and in mouse embryonic fibroblasts, and IRF7 is thought to be an important transcriptional factor that affects anti-viral responses by inducing the production of type I IFN (Honda et al., 2005).

\subsection{Treatment of pediatric-onset lupus nephritis by direct targeting the IFN-p/RIG- I/IRF7 pathway}

Although the functional significance of IRF7 expression in mesangial cells remains to be elucidated, our recent observations suggest that the IFN-ץ/RIG-I/IRF7 signaling pathways may be involved in the pathogenesis of lupus nephritis. We believe that the involvement of the newly observed IFN-ץ/RIG-I/IRF7 pathway in mesangial cells may contribute to mesangial inflammation, and the intervention of this signaling pathway may lead to the development of optimal future therapeutic strategies for patients with lupus nephritis. However, further clinical and experimental issues remain to be examined in future studies.

\section{Acknowledgements}

Part of these studies was supported by a Grant from the Japan Society for the Promotion of Science (\#21591259 and \#22591175) and a grant from The Mother and Child Health Foundation, Osaka, Japan.

\section{Conflict of interest statement}

None declared.

\section{References}

Aizawa-Yashiro T, Tsuruga K, Watanabe S, Oki E, Ito E, Tanaka H (2011). Novel multidrug therapy for children with cyclosporine-resistant or -intolerant nephrotic syndrome. Pediatr Nephrol DOI: 10.1007/s00467-011-1876-Z

Asamiya Y, Uchida K, Otsubo S, Takei T, Nitta K (2009). Clinical assessment of tacrolimus therapy in lupus nephritis: One-year follow-up study in a single center. Nephron Clin Pract 113: c330-c336. 
Austin HA \& Balow JE (1999) Natural history and treatment of lupus nephritis. Semin Nephrol 19: 2-11.

Austin HA, Muenz LR, Joyce KM, Antonnovych TT \& Balow JE (1984) Diffuse proliferative lupus nephritis: Identification of specific pathologic features affecting renal outcome. Kidney Int 25: 689-695.

Bao H, Liu ZH, Xie HL, Hu WX, Zhang HT \& Li LS (2008) Successful treatment of class V+IV lupus nephritis with multitarget therapy. J Am Soc Nephrol 19: 2001-2010.

Burkhardt H \& Kalden JR (1997) Xenobiotic immunosuppressive agents: therapeutic effects in animal models of autoimmune diseases. Rheumatol Int 17: 85-90.

Chan TM, Li FK, Tang CSO, Wong RWS, Fang GX, Ji YL, Lau CS, Wong AKM, Tong MKL, Chan KW \& Lai KN (2000) Efficacy of mycophenolate mofetil in patients with diffuse proliferative lupus nephritis. N Engl J Med 343:1156-1162

Chan TM, Tse KC, Tang CSO, Lai KN \& Li FK (2005) Long-term outcome of patients with diffuse proliferative lupus nephritis treated with prednisolone and oral cyclophosphamide followed by azathioprine. Lupus 14: 265-272.

Coppo R, Amore A, Peruzzi L, Vergano L \& Camilla R (2010). Innate immunity and IgA nephropathy. J Nephrol 23: 626-632.

Davies TH, Ning YM, Sanchez ER (2005) Differential control of glucocorticoid receptor hormone-binding function by tetratricopeptide repeat (TPR) proteins and immunosuppressive ligand FK506. Biochemistry 44: 2030-2038.

Duddridge M \& Powell RJ (1997) Treatment of severe and difficult cases of systemic lupus erythematosus with tacrolimus. A report of three cases. Ann Rheum Dis 56: 690-692.

Hara S, Umino D, Someya T, Fujinaga S, Ohtomo Y, Murakami H \& Shimizu T (2009) Protective effects of mizoribine on cyclosporine A nephropathy in rats. Pediatr Res 66: 524-527

Honda K, Yanai H, Negishi H, Asagiri M, Sato M, Mizutani T, Shimada N, Oba Y, Takaoka A, Yoshida N \& Taniguchi T (2005). IRF-7 is the master regulator of type-I interferon-dependent immune responses. Nature 434: 772-777.

Ikezumi Y, Kanno K, Koike H, Tomita M, Uchiyama M, Shimizu F, Kawachi H (2002) FK506 ameliorate proteinuria and glomerular lesions induced by anti-Thy 1.1 monoclonal antibody 1-22-3. Kidney Int 61: 1339-1350.

Ikezumi Y, Suzuki T, Karasawa T, Kawachi H, Nikolic-Paterson DJ \& Uchiyama M (2008) Use of mizoribine as a rescue drug for steroid-resistant pediatric IgA nephropathy. Pediatr Nephrol 23: 645-650.

Imaizumi T, Matsumiya T, Yoshida H, Naraoka T, Uesato R, Ishibashi Y, Ota K, Toh S, Fukuda S \& Satoh K (2009). Tumor-necrosis factor-a induces retinoic acid-inducible gene-I in rheumatoid fibroblast-like synoviocytes. Immunol Lett 122: 89-93.

Imaizumi T, Tanaka H, Tajima A, Tsuruga K, Oki E, Sashinami H, Matsumiya T, Yoshida H, Inoue I \& Ito E (2010) Retinoic acid-inducible gene-I (RIG-I) is induced by IFN-ү in human mesangial cells in culture: possible involvement of RIG-I in the inflammation in lupus nephritis. Lupus 19: 830-836.

Itoh H, Komatsuda A, Wakui H, Miura AB \& Tashima Y (1999) Mammalian HSP60 is a major target for an immunosuppressant mizoribine. J Biol Chem 274: 35147- 35151.

Kamata K, Okubo M, Uchiyama T, Masaki Y, Kobayashi Y \& Tanaka T (1984) Effect of mizoribine on lupus nephropathy of New Zealand black/white F1 hybrid mice. Clin Immunol Immunopathol 33: 31-38.

Kawai S \& Yamamoto K (2006) Safety of tacrolimus, an immunosuppressive agent, in the treatment of rheumatoid arthritis in elderly patients. Rheumatology (Oxford) 45: 441-444. 
Kawasaki Y, Hosoya M, Suzuki J, Onishi N, Takahashi A, Isome M, Nozawa R \& Suzuki H (2004) Efficacy of multidrug therapy combined with mizoribine in children with diffuse $\operatorname{Ig} \mathrm{A}$ nephropathy in comparison with multidrug therapy without mizoribine and with methyprednisolone pulse therapy. Am J Nephrol 24: 576-581.

Kikuchi Y, Imakiire T, Yamada M, Saigusa T, Hyodo T, Hyodo N, Suzuki S \& Miura S (2005) Mizoribine reduces renal injury and macropharge infiltration in non-insulindependent diabetic rats. Nephrol Dial Transplant 20: 1573-1581.

Kuroda T, Hirose S, Tanabe N, Sato H, Nakatsue T, Ajiro J, Wada Y, Murakami S, Hasegawa H, Ito S, Sakatsume M, Nakano M \& Gejyo F (2007) Mizoribine therapy for patients with lupus nephritis: the association between peak mizoribine concentration and clinical efficacy. Mod Rheumatol 17: 206-212.

Lai KN, Tang SCW \& Mok CC (2005) Treatment for lupus nephritis: a revisit. Nephrology (Carlton) 10: 180-188.

Lanata CM, Mahmood T, Fine DM \& Petri M (2010) Combination therapy of mycophenolate mofetil and tacrolimus in lupus nephritis. Lupus 19: 935-940.

Lehman TJ \& Onel K (2000) Intermittent intravenous cyclophosphamide arrests progression of the renal chronicity index in childhood systemic lupus erythematosus. J Pediatr 136: 243-247.

Maruyama M, Yamasaki Y, Sada K, Sarai A, Ujike K, Maeshima Y, Nakamura Y, Sugiyama H \& Makino H (2006) Good response of membranous lupus nephritis to tacrolimus. Clin Nephrol 65: 276-279.

Mok CC, Tong KH, To CH, Siu YP, \& Au TC (2005) Tacrolimus for induction therapy of diffuse proliferative lupus nephritis: an open-labeled pilot study. Kidney Int 68: 813-817.

Moroni G, Doria A \& Ponticelli C. Cyclosporine (CsA) in lupus nephritis: assessing the evidence. Nephrol Dial Transplant 2009; 24: 15-20.

Mosca M, Bencivelli W, Vitali C, Carrai P, Neri R \& Bombardieri S (2000) The validity of the ECLAM index for the retrospective evaluation of disease activity in systemic lupus erythematosus. Lupus 9: 445-450.

Niaudet P (2000) Treatment of lupus nephritis in children. Pediatr Nephrol 14: 158-166.

Nozu K, Iijima K, Kamioka I, Fujita T, Yoshiya K, Tanaka R, Nakanishi K, Yoshikawa N \& Matsuo M (2006) High-dose mizoribine treatment for adolescents with systemic lupus erythematosus. Pediatr Int 48: 152-157.

Patole PS, Pawar RD, Lech M, Zecher D, Schmidt H, Segerer S, Ellwart A, Henger A, Kretzler M \& Anders HJ (2006). Expression and regulation of Toll-like receptors in lupus-like immune complex glomerulomephritis of MRL-Fas (lpr) mice. Nephrol Dial Transplant 21: 3062-3073.

Politt D, Heintz B, Floege J \& Mertens PR (2004). Tacrolimus- (FK506) based immunosuppression in severe systemic lupus erythematosus. Clin Nephrol 62: 49-53.

Posalski JD, Ishimori ML, Wallace DJ \& Weisman MH (2009) Does mycophenolate mofetile prevent extra-renal flares in systemic lupus eruthematosus? Results from an observational study of patients in a single practice treated for up to 5 years. Lupus 18: 516-521.

Rihova Z, Vankova Z, Maixnerova D, Dostal C, Jancova E, Honsova E, Merta M, Rysava R \& Tesar V (2007) Treatment of lupus nephritis with cyclosporine- An outcome analysis. Kidney Blood Press Res 30: 124-128.

Robson MG (2009). Toll-like receptors and renal disease. Nephron Exp Nephrol 113: e1-e7. 
Sakano T, Ohta T, Kinoshita Y. Fujiwara M \& Wakai M (2004) Treatment of steroid-resistant systemic lupus erythematosus with extremely low dose of cyclosporine A. Pediatr Int 46: 468-470.

Sato N, Shiraiwa K, Kai K, Watanabe A, Ogawa S, Kobayashi Y, Yamagishi-Imai H, Utsunomiya Y \& Mitarai T (2001) Mizoribine ameliorates the tubulointerstitial fibrosis of obstructive nephropathy. Nephron 89: 177-185.

Shimizu H, Takahashi M, Takeda S, Tahara K, Inoue S, Nakamata Y, Kaneko T, Takeyoshi I, Morishita Y \& Kobayashi E (2003) Effect of conversion from cyclosporine A to mizoribine on transplant arteriosclerosis in rat aortic allograft models. Microsurgery 23: 454-457

Sinclair A, Appel G, Dooley MA, Ginzler E, Isenberg D, Jayne D, Wofsy D \& Solomons N (2007) Mycophenolate mofetil as induction and maintenance therapy for lupus nephritis: rationale and protocol for the randomized, controlled Aspreva Lupus Management Study (ALMS). Lupus 16: 972-980.

Sonda K, Takahashi K, Tanabe K, Fuchinoue S, Hayasaka Y, Kawaguchi H, Teraoka S, Toma H \& Ota K (1996) Clinical pharmacokinetic study of mizoribine in renal transplantation patients. Transplant Proc 28: 3643-3648.

Suzuki K, Imaizumi T, Oki E, Tsugawa K, Ito E \& Tanaka H (2007) Expression of retinoic acid-inducible gene-I in lupus nephritis. Nephrol Dial Transplant 22: 2407-2409.

Suzuki K, Saito K, Tsujimura S, Nakayamada S, Yamaoka K, Sawamukai N, Ieata S, Nawata M, Nakano K \& Tanaka Y (2010) Tacrolimus, a calcineurin inhibitor, overcomes treatment unresponsiveness mediated by p-glycoprotein on lymphocytes in refractory rheumatoid arthritis. J Rheumatol 37: 512-520.

Suzuki K, Tanaka H, Tsugawa K \& Ito E (2006) Effective treatment with cyclosporine A of a child with systemic lupus erythematosus resistant to cyclophosphamide pulse therapy. Tohoku J Exp Med 208: 355-359.

Szeto CC, Kwan BCH, Lai FMM, Tam LS, Li EKM, Chow KM, Gang W \& Li PKT (2008) Tacrolimus for the treatment of systemic lupus erythematosus with pure class $\mathrm{V}$ nephritis. Rheumatology (Oxford) 47: 1678-1681.

Takahashi S, Taniguchi Y, Nakashima A, Arakawa T, Kawai T, Doi S, Ito T, Masaki T, Kohno N \& Yorioka N (2009) Mizoribine suppresses the progression of experimental peritoneal fibrosis in a rat model. Nephron Exp Nephrol 112: e59-e69.

Takahashi S, Wakui H, Gustafsson JA, Zilliacus J \& Itoh H (2000) Functional interaction of the immunosuppressant mizoribine with the 14-3-3 protein. Biochem Biophys Res Commun 274: 87-92.

Takeuchi S, Hiromura K, Tomioka M, Takahashi S, Sakairi T, Maeshima A, Kaneko Y, Kuroiwa T \& Nojima Y (2010) The immunosuppressive drug mizoribine directory prevents podocyte injury in puromycin aminosucleoside nephrosis. Nephron Exp Nephrol 116: e3-e10

Tanaka H, Oki E, Tsuruga K, Aizawa-Yashiro T, Ito Y, Sato N, Kawasaki Y \& Suzuki J (2010) Mizoribine attenuates renal injury and macrophage infiltration in patients with severe lupus nephritis. Clin Rheumatol 29: 1049-1054.

Tanaka H, Oki E, Tsugawa K, Nonaka K, Suzuki K \& Ito E (2007a). Effective treatment of young patients with pediatric-onset, long-standing lupus nephritis with tacrolimus given as a single daily dose: An open-label pilot study. Lupus 16: 896-900.

Tanaka H, Oki E, Tsuruga K, Sato N, Matsukura H, Matsunaga A, Kondo Y, Suzuki J (2008a) Mizoribine treatment of young patients with severe lupus nephritis: A 
clinicopathologic study by the Tohoku Pediatric Study Group. Nephron Clin Pract 110: c73-c79.

Tanaka H, Oki Es, Tsugawa K, Suzuki K, Tsuruga K \& Ito E (2007b) Long-term intermittent pulse therapy with mizoribine attenuates histologic progression in young patients with severe lupus nephritis: Report of two patients. Nephrology (Carlton) 12: 376-379.

Tanaka H, Oki E, Tsuruga K, Yashiro T, Hanada I \& Ito E (2009) Management of young patients with lupus nephritis using tacrolimus administered as a single daily dose. Clin Nephrol 72: 430-436.

Tanaka H, Suzuki K, Nakahata T, Tsugawa K, Ito E \& Waga S (2003) Mizoribine oral pulse therapy for patients with disease flare of lupus nephritis. Clin Nephrol 60: 390-394.

Tanaka H, Tateyama T \& Waga S (2001) Methylprednisolone pulse therapy in Japanese children with severe lupus nephritis. Pediatr Nephrol 16: 817-819.

Tanaka H, Tsugawa K, Nakahata T, Kudo M, Suzuki K \& Ito E (2005) Implication of peak serum level of mizoribine for control the serum anti-dsDNA antibody titer in patients with lupus nephritis. Clin Nephrol 63: 417-422.

Tanaka H, Tsugawa K, Oki E, Suzuki K \& Ito E (2008b) Mizoribine intermittent pulse therapy for induction therapy for systemic lupus erythematosus in children: an open-label pilot study with five newly diagnosed patients. Clin Rheumatol 27: 85-89.

Tanaka H, Tsugawa K, Oki E, Suzuki K, Waga S \& Ito E (2007c) Long-term mizoribine intermittent pulse therapy, but not azathioprine therapy, attenuated histologic progression in a patient with severe lupus nephritis. Clin Nephrol 68: 198-200.

Tanaka H, Tsugawa K, Suzuki K, Nakahata T \& Ito E (2006) Long-term mizoribine intermittent pulse therapy for young patients with flare of lupus nephritis. Pediatr Nephrol 21: 962-966.

Tanaka H, Tsugawa K, Tsuruga K, Nakahata T, Suzuki K, Ito E \&Waga S (2004) Mizoribine for the treatment of lupus nephritis in children and adolescents. Clin Nephrol 62: 412-417.

Tse KC, Lam MF, Tang SCW, Tang CSO \& Chan TM (2007) A pilot study on tacrolimus treatment in membranous or quiescent lupus nephritis with proteinuria resistant to angiotensin inhibitor or blockade. Lupus 16: 46-51.

Tsugawa K, Oki E, Suzuki K, Imaizumi T, Ito E \& Tanaka H (2008) Expression of mRNA for functional molecules in urinary sediment in glomerulonephritis. Pediatr Nephrol 23: 395-401.

Watanabe S, Tsuruga K, Aizawa-Yashiro T, Oki E, Ito E \& Tanaka H (2011) Addition of mizoribine to the prednisolone plus tacrolimus treatment regimen in a patient with lupus flare. Rheumatol Int DOI: 10.1007/s00296-011-1858-2.

Yang LY, Chen WP \& Lin CY (1994) Lupus nephritis in children. A review of 167 patients. Pediatrics 94:335-340

Yokota S (2002) Mizoribine: Mode of action and effects in clinical use. Pediatr Int 44: 196-198.

Yoneyama M, Kikuchi M, Natsukawa T, Shinobu N, Imaizumi T, Miyagishi M, Taira K, Akira S \& Fujita T (2004). The RNA helicase RIG-I has an essential function in double-stranded RNA-induced innate antiviral responses. Nat Immunol 5: 730-737.

Yumura W, Suganuma K, Uchida K, Moriyama T, Otsubo S, Takei T, Naito M, Koike M, Nitta K \& Nihei H (2005) Effects of long-term treatment with mizoribine in patients with proliferative lupus nephritis. Clin Nephrol 64: 28-34. 


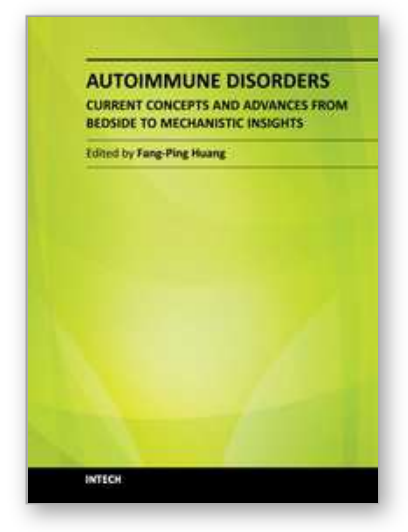

\author{
Autoimmune Disorders - Current Concepts and Advances from \\ Bedside to Mechanistic Insights \\ Edited by Dr. Fang-Ping Huang
}

ISBN 978-953-307-653-9

Hard cover, 614 pages

Publisher InTech

Published online 14, November, 2011

Published in print edition November, 2011

Autoimmune disorders are caused due to break down of the immune system, which consequently fails in its ability to differentiate "self" from "non-self" in the context of immunology. The diseases are intriguing, both clinically and immunologically, for their diversified clinical phenotypes and complex underlying immunological mechanisms. This book offers cutting-edge information on some of the specific autoimmune disease phenotypes, respective diagnostic and prognostic measures, classical and new therapeutic options currently available, pathogenesis and underlying mechanisms potentially involved, and beyond. In the form of Open Access, such information is made freely available to clinicians, basic scientists and many others who will be interested regarding current advances in the areas. Its potential readers will find many of the chapters containing in-depth analysis, interesting discussions and various thought-provoking novel ideas.

\title{
How to reference
}

In order to correctly reference this scholarly work, feel free to copy and paste the following:

Hiroshi Tanaka and Tadaatsu Imaizumi (2011). Treatment of Pediatric-Onset Lupus Nephritis: A New Option of Less Cytotoxic Immunosuppressive Therapy, Autoimmune Disorders - Current Concepts and Advances from Bedside to Mechanistic Insights, Dr. Fang-Ping Huang (Ed.), ISBN: 978-953-307-653-9, InTech, Available from: http://www.intechopen.com/books/autoimmune-disorders-current-concepts-and-advances-from-bedsideto-mechanistic-insights/treatment-of-pediatric-onset-lupus-nephritis-a-new-option-of-less-cytotoxicimmunosuppressive-therap

\section{INTECH}

open science | open minds

\section{InTech Europe}

University Campus STeP Ri

Slavka Krautzeka 83/A

51000 Rijeka, Croatia

Phone: +385 (51) 770447

Fax: +385 (51) 686166

www.intechopen.com

\section{InTech China}

Unit 405, Office Block, Hotel Equatorial Shanghai

No.65, Yan An Road (West), Shanghai, 200040, China

中国上海市延安西路 65 号上海国际贵都大饭店办公楼 405 单元

Phone: +86-21-62489820

Fax: $+86-21-62489821$ 
(C) 2011 The Author(s). Licensee IntechOpen. This is an open access article distributed under the terms of the Creative Commons Attribution 3.0 License, which permits unrestricted use, distribution, and reproduction in any medium, provided the original work is properly cited. 